\title{
A Genome-Wide Search for Linkage-Disequilibrium With Type 1 Diabetes in a Recent Genetically Isolated Population From the Netherlands
}

\author{
Norbert Vaessen, ${ }^{1}$ Peter Heutink, ${ }^{1}$ Jeanine J. Houwing-Duistermaat, ${ }^{1}$ Pieter J.L.M. Snijders, ${ }^{1}$ \\ Tessa Rademaker, ${ }^{1}$ Leon Testers, ${ }^{1}$ Manou R. Batstra, ${ }^{2}$ Lodewijk A. Sandkuijl, ${ }^{1}$ \\ Cornelia M. van Duijn, ${ }^{1}$ and Ben A. Oostra ${ }^{1}$
}

\begin{abstract}
Type 1 diabetes has a substantial genetic component, with consistent evidence for a susceptibility locus in the HLA-DR/DQ region (chromosome 6p) and the insulin gene region (chromosome 11p). Genome scans have identified $>18$ other genomic regions that may harbor putative type 1 diabetes genes. However, evidence for most regions varies in different data sets. Given the genetic heterogeneity of type 1 diabetes, studies in homogeneous genetically isolated populations may be more successful in mapping susceptibility loci than in complex outbred populations. We describe a genomewide search in a recently Dutch isolated population. We identified 43 patients that could be traced back to a common ancestor within $\mathbf{1 5}$ generations and performed a genome-wide scan using a combined linkage- and association-based approach. In addition to the HLA locus, evidence for type 1 diabetes loci was observed on chromosome 8q24 (marker D8S1128) and on chromosome 17q24 (marker D17S2059). Both the 8q and 17q localization are supported by allele-sharing at adjacent markers in affected individuals. Statistical evidence for a conserved ancestral haplotype was found for chromosome 8q24. Diabetes 51:856-859, 2002
\end{abstract}

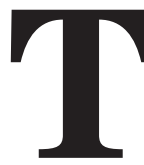

ype 1 diabetes is characterized by an absolute insulin deficiency caused by autoimmune destruction of insulin-producing $\beta$-cells in the pancreas. Both genetic and environmental factors appear to be involved (1). Several haplotypes at the HLA class II region on chromosome 6p21 are associated with an increased risk to develop type 1 diabetes (2). Also, $>90 \%$ of type 1 diabetes patients of European ancestry have at least one copy of the HLA-DR3 or DR4 allele, as compared with $45 \%$ in the general population. Almost $40 \%$ of type 1 diabetic patients have both alleles, although $3 \%$ is ex-

From the ${ }^{1}$ Genetic Epidemiology Unit, Department of Epidemiology and Biostatistics, Department of Clinical Genetics, Erasmus Medical Center Rotterdam, Rotterdam, the Netherlands; and the ${ }^{2}$ Department of Pediatrics, Erasmus Medical Center Rotterdam, Rotterdam, the Netherlands.

Address correspondence and reprint requests to Prof. Dr. B.A. Oostra, Genetic Epidemiology Unit, Department of Clinical Genetics, Erasmus Medical Center Rotterdam, P.O. Box 1738, 3000 DR Rotterdam, the Netherlands. E-mail: oostra@kgen.fgg.eur.nl.

Received for publication 29 June 2001 and accepted in revised form 15 November 2001. pected based on the frequency of the general population $(3,4)$. Numerous studies have found several other genotypes within the HLA region to be associated with type 1 diabetes (referred to as IDDM1). In addition, the insulin gene on chromosome 11p15 (IDDM2) has been implicated in the pathogenesis of type 1 diabetes (5).

The HLA class II region and insulin region, identified using association analysis of candidate genes, account for $\sim 50 \%$ of the total familial clustering of type 1 diabetes (6). Several genome-wide linkage studies have identified $>18$ other genomic regions that may harbor susceptibility loci for type 1 diabetes; however, many findings could not be reproduced in other studies $(7,8)$. Although this may suggest that some of the initial linkage findings have been false-positive results, it may also reflect genetic heterogeneity of type 1 diabetes in diverse ethnic groups.

Mapping disease genes in a genetically isolated population rather than a general population of case subjects or families received considerable attention $(9,10)$. A benefit of this strategy is that complex traits are expected to be more homogeneous in isolated populations because of the small number of founders and genetic drift, increasing the power of linkage analysis. In the isolated population, chances are higher that patients have inherited a disease gene from a common ancestor. Since adjacent markers on a chromosome are often transmitted together, patients from recently (since 5-15 generations) isolated populations with a common ancestor are likely to share considerable stretches of DNA around disease gene(s) (11). Until now, the focus has been on populations of prolonged isolation, such as the Finnish and Icelandic populations $(12,13)$.

We ascertained 46 patients with type 1 diabetes in an isolated village in the southwestern region of the Netherlands. Genealogical information was collected for all 46 patients and revealed that 43 patients (93\%) could be traced back to a common ancestor within 15 generations. In Fig. 1, the genealogical lineages of these patients are shown, based on the shortest number of meioses separating them from a common ancestor. This figure represents a simplified example of the genealogical structure of this population. In reality, most patients are related with each other in several ways via multiple common ancestors. To ensure a homogeneous study sample, the analyses in this 


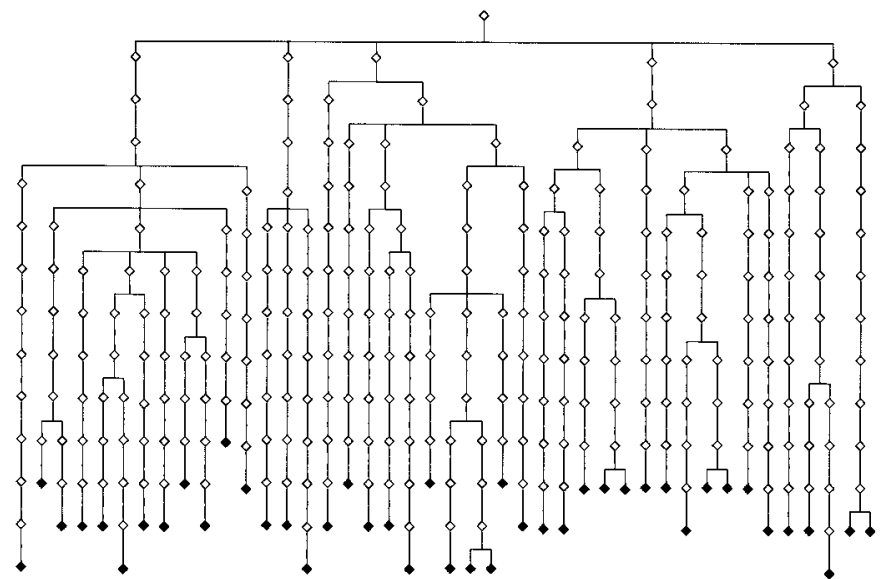

FIG. 1. Genealogical lineages of 43 type 1 diabetic patients that could be traced back to a common ancestor within 15 generations. The figure is based on the shortest number of meioses separating each person from this common ancestor.

study are restricted to these 43 patients who are related within 15 generations.

Characteristics of the patients are given in Table 1. Only 33 patients (73.3\%) carried the HLA-DR3 or DR4 allele, and only 8 (17.8\%) were heterozygous for the DR3/DR4 allele. These frequencies were lower than expected frequencies of $90 \%(P<0.00006)$ and $40 \%(P=0.017)$, which are found in most Caucasian populations $(3,5)$, suggesting that other type 1 diabetes genes play a more important role in this population. The lower frequency of the high-risk HLA alleles makes this population very suitable for mapping of new type 1 diabetes genes.

We performed a genome scan using the 43 patients and 86 first-degree relatives. We found evidence for combined linkage and association with three markers: marker D6S1014 in the HLA-region on chromosome 6p $(P=0.009$, $\lambda=0.46)$, marker D8S1128 on chromosome 8q24 $(P=$ $0.003, \lambda=0.45$ ), and marker D17S2059 on chromosome $17 \mathrm{q} 24(P=0.012, \lambda=0.65)$. To confirm that the non-HLA regions represent true-positive findings, three additional analyses were performed. First, the risk for type 1 diabetes was determined for the associated alleles of markers D8S1128 and D17S2059 as well as for flanking markers in these regions. We hypothesized that if the initial findings represent true positive findings, flanking markers in these regions should also be associated with increased risk for diabetes. Although the flanking markers in the $8 \mathrm{q}$ region did not show a $P$ value $<0.016$ in the initial genome scan, the ancestral alleles of markers D8S592, D8S1179, D8S1128, and D8S1100 were all associated with an in-

\section{TABLE 1}

Characteristics of 46 type 1 diabetic patients

TABLE 2

Case-control analysis of flanking markers on chromosome $8 \mathrm{q}$

\begin{tabular}{lcccc}
\hline & $\begin{array}{c}\text { Frequency } \\
\text { in control } \\
\text { subjects } \\
(\%)\end{array}$ & $\begin{array}{c}\text { Frequency } \\
\text { in case } \\
\text { subjects } \\
(\%)\end{array}$ & $\begin{array}{c}\text { Risk } \\
(95 \% \mathrm{CI})\end{array}$ & $P$ \\
$\begin{array}{l}\text { Marker and } \\
\text { genotype }\end{array}$ & & & & \\
\hline $\begin{array}{l}\text { D8S592 (125 cM, } \\
\text { allele 150 }\end{array}$ & & & & \\
$\quad$ bp) & 69.7 & 48.6 & 1 & \\
0 & 15.2 & 40.0 & $3.8(1.1-12.6)$ & 0.03 \\
1 & 15.2 & 11.4 & $1.1(0.3-4.7)$ & 0.91 \\
2 & & Trend & $1.4(0.7-2.8)$ & 0.16
\end{tabular}

D8S1179 (136 cM, allele 181

$0^{\mathrm{bp})}$
1
2

D8S1128 (142 cM, allele 243 bp) 0

1 2

D8S1100 (160 cM, allele 192

$\begin{array}{ll} & \text { bp) } \\ 0 & \\ 1 & \end{array}$

\section{9 \\ 50.0 \\ 3.1}

20.6

58.8

20.6

Trend

$$
\begin{array}{cl}
1 & \\
2.7(0.9-8.1) & 0.08 \\
14.9(1.5-146.2) & 0.02 \\
3.3(1.4-146.2) & 0.008
\end{array}
$$

84.4
15.6
0

43.8
46.9
9.4
Trend $\begin{array}{ll}5.8(1.7-19.2) & 0.004 \\ 6.4(2.0-19.7) & 0.0005^{*}\end{array}$

43.8
43.8
12.5

1 $1.6(0.5-4.7) \quad 0.40$ $2.8(0.7-11.9) \quad 0.16$ $1.7(0.8-3.3) \quad 0.08$
Results of the case-control analysis for markers on chromosome 8q. Results are based on the ancestral allele as identified in the initial screen. $* P$ value calculated by Fisher's exact test.

creased risk for type 1 diabetes (Table 2). Also, in the 17q region, allele-sharing at additional markers by affected individuals was observed. The ancestral alleles of the adjacent markers D17S809, D17S1290, D17S2059, and D17S1301 were all associated with a highly increased risk for type 1 diabetes (Table 3). Second, after this observation, a trend analysis was performed for each of these markers. We hypothesized that if the 8q24 and 17q24 localizations represent true susceptibility loci, the risk for diabetes should increase with the number of ancestral alleles present for each marker. For chromosome 8, the odds ratio (OR) for trend reached a maximum of 6.4 at D8S1128 $(P=0.0005)$, whereas the lowest OR was observed for marker D8S592 (OR 1.4, $P=0.16$ ) and D8S1100 (OR 1.7, $P=0.08$ ), located at $\sim 18 \mathrm{cM}$ on either side of D8S1128 (Table 2). This suggests that a susceptibility gene is probably located around D8S1128. For chromosome 17, a significant trend was observed for all four markers, in particular for D17S2059 (OR 3.1, $P=0.0005$ ) (Table 3). Finally, we investigated whether affected individuals showed evidence for an ancestral haplotype surrounding the markers identified in the initial screen. Haplotypes within the $8 \mathrm{q}$ region were associated with a highly increased risk for type 1 diabetes, supporting the presence of a true susceptibility locus inherited from a common ancestor (Table 4). In the $17 \mathrm{q}$ region, the distribution of two-marker haplotypes was not significantly different between case and control subjects (data not shown).

To study a possible interaction between the $8 \mathrm{q}$ or $17 \mathrm{q}$
Male sex

Mean age at time of diagnosis (years)

Presence of detectable GAD antibodies

Presence of detectable IA2 antibodies

Presence of both antibodies

Frequency of high-risk HLA genotypes

HLA-DR3 and/or HLA-DR4 allele

Heterozygous HLA-DR3/DR4
Data are $\%$ or means (range).

$15(1-30)$
39
24
15
73.3
17.8


TABLE 3

Case-control analysis of flanking markers on chromosome $17 \mathrm{q}$

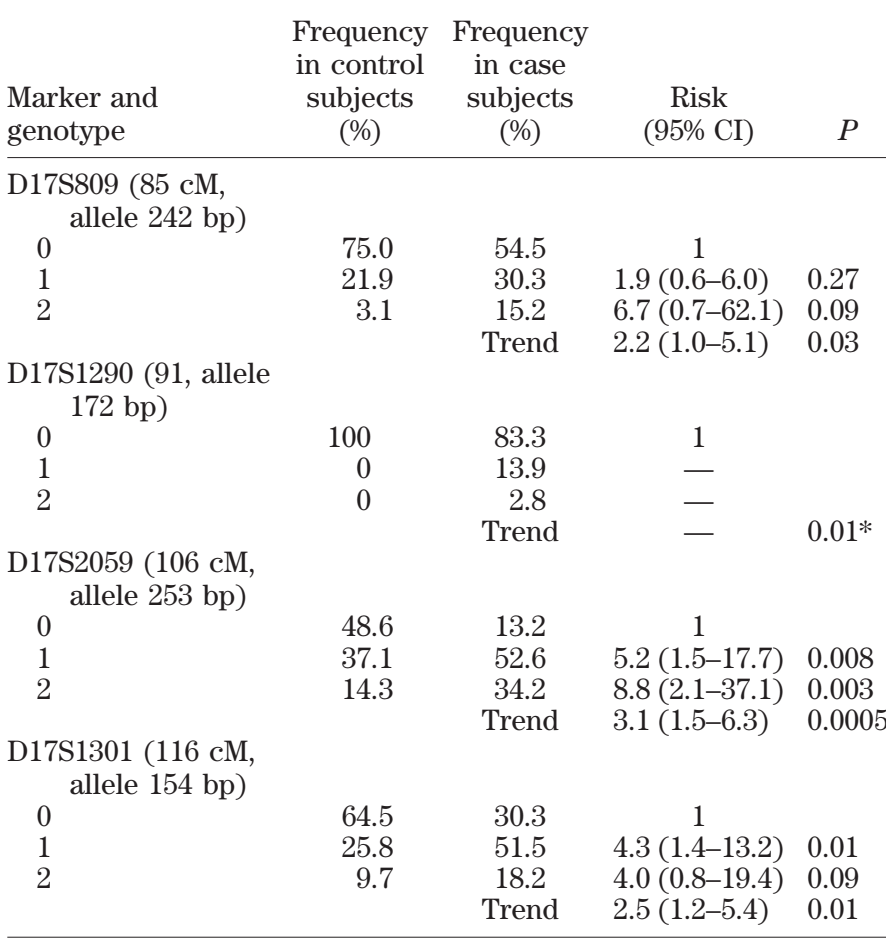

Results of the case-control analysis for markers on chromosome $17 \mathrm{q}$ Results are based on the ancestral allele as identified in the initial screen. $* P$ value calculated by Fisher's exact test. The risk for marker D17S1290 could not be calculated because the ancestral allele was not present in control subjects.

region and the high-risk HLA alleles, a stratified analysis was performed. In this analysis, the distribution of ancestral alleles, as identified in the initial genome scan, was assessed in individuals with or without the HLA-DR3 or DR4 allele. The ancestral alleles of marker D8S1179 $(P=$ $0.05)$ and $\mathrm{D} 8 \mathrm{~S} 1128(P=0.0005)$ were more frequently observed in patients with the high-risk HLA-DR4 allele than in patients without the HLA-DR4 allele, suggesting an interaction between the susceptibility gene on chromosome 8q24 and the HLA-DR locus. No difference in distribution of the ancestral alleles in the $17 q$ region was observed between the different HLA-subgroups (data not shown).

Both the $8 \mathrm{q} 24$ and $17 \mathrm{q} 24$ localization are supported by statistical trend analysis and by allele-sharing at additional markers in affected individuals. Very weak evidence of linkage of chromosome 8 to type 1 diabetes, $\sim 5-25 \mathrm{cM}$ centromeric to our location, has been reported previously $(8,14)$. Although linkage to this region could not be replicated in a follow-up analysis by Cucca et al. (15), our study in a homogeneous population supports the initial findings. No evidence for linkage to chromosome 17 has been reported before. Therefore, this locus still remains to be confirmed.

Although it has recently been argued that old genetic isolates will not prove to be more valuable than outbred populations for linkage-disequilibrium mapping of common variants underlying complex disease $(16,17)$, our study in a recently isolated population has yielded promising findings.

\section{RESEARCH DESIGN AND METHODS}

Patients with type 1 diabetes were ascertained from a genetically isolated village in the southwest region of the Netherlands. This village was founded by $\sim 150$ people in the middle of the 18th century, and up until the last decades, descendants of these founders have lived in social isolation, with minimal immigration $(<5 \%)$. From the year 1848 on, the population has expanded from 700 up to 20,000 inhabitants. With help from the local health care centers, we were able to recruit 60 individuals diagnosed with type 1 diabetes via local physicians. Medical records covering the last 20 years were available for all patients. The overall participation rate was $77 \%(n=46)$. All 46 participants completed a questionnaire on family and medical history and gave blood samples for DNA extraction and detection of autoantibodies. Plasma samples were stored at $-70^{\circ} \mathrm{C}$ within $12 \mathrm{~h}$ after venepuncture. GAD and IA2 antibodies were tested by immunoprecipitation as previously described (18). We applied the American Diabetes Association criteria for the diagnosis of diabetes to confirm the diagnosis. A diagnosis of type 1 diabetes was made if diabetes was diagnosed before the age of 30 years and patients were insulin-dependent within 1 year after diagnosis. For each patient, at least two first-degree relatives were asked to give a blood sample to be able to reconstruct haplotypes.

Collection of genealogical information. To determine which of the subjects were descended primarily from the original founders of the isolated village, a genealogical search was completed for each patient, using church and municipal records of births, marriages, and deaths. Genealogical lineages for each patient were traced back 15 generations.

Genotyping. DNA samples were obtained from peripheral white blood cells. The genome screen was performed using 391 markers covering the whole

TABLE 4

Haplotype analysis chromosome 8q

\begin{tabular}{|c|c|c|c|c|c|c|c|}
\hline Marker & $\mathrm{cM}$ & Allele (bp) & Haplotype & $\begin{array}{l}\text { Frequency in control } \\
\text { subjects (\%) }\end{array}$ & $\begin{array}{c}\text { Frequency in } \\
\text { case subjects (\%) }\end{array}$ & Risk $(95 \% \mathrm{CI})$ & $P$ \\
\hline D8S592 & 125 & 150 & $\begin{array}{l}\text { Heterozygous } \\
\text { Homozygous }\end{array}$ & $\begin{array}{l}4.8 \\
0\end{array}$ & $\begin{array}{c}15.3 \\
0 \\
\text { Trend }\end{array}$ & $\begin{array}{c}3.5(0.9-13.4) \\
-\end{array}$ & 0.06 \\
\hline D8S1179 & 136 & 181 & $\begin{array}{l}\text { Heterozygous } \\
\text { Homozygous }\end{array}$ & $\begin{array}{l}1.6 \\
0\end{array}$ & $\begin{array}{c}12.1 \\
3.0 \\
\text { Trend }\end{array}$ & $\begin{array}{c}9.0(1.1-74.0) \\
-\overline{-} \\
9.5(1.2-73.4)\end{array}$ & $\begin{array}{l}0.04 \\
0.004^{*}\end{array}$ \\
\hline D8S1128 & 142 & 243 & $\begin{array}{l}\text { Heterozygous } \\
\text { Homozygous }\end{array}$ & $\begin{array}{l}3.2 \\
0\end{array}$ & $\begin{array}{c}10.6 \\
1.5 \\
\text { Trend }\end{array}$ & $\begin{array}{c}3.7(0.7-18.4) \\
-\overline{-} \\
4.0(1.0-18.5)\end{array}$ & $\begin{array}{l}0.07 \\
0.05^{*}\end{array}$ \\
\hline
\end{tabular}

Results of the case-control analysis for haplotypes on chromosome 8q. Haplotypes are based on the ancestral alleles as identified in the initial screen. $* P$ value calculated by Fisher's exact test. 
genome, with an average spacing of $10 \mathrm{cM}$ and an average heterozygosity of 0.75 (version 6 of the Weber lab screening set, see http://research.marshfield clinic.org/genetics/sets/combo.html). PCR products were pooled and loaded on an ABI377 automated sequencer, and data were analyzed using ABI GeneScan3.1 and ABI Genotyper2.1 software.

The HLA-DR3 and -DR4 alleles were determined in all participants. DR3 amplification was performed with forward primer $(5$ '-TTGTCCACCCGGC CCCGCT-3'; DR3, Gibco BRL), and reverse primer (5'-CACGTTTCTTG GAGTACTCTACGTCTGTGT-3'; DR3, Gibco BRL). DR4 amplification was performed with forward primer (5'-GTTTCTTGGAGCAGGTTAAAC-3'; DR4, Gibco BRL), and reverse primer (5'-TTCTCGCCGCTGCACTGTGAA3'; DR4, Gibco BRL).

Statistical analysis. A whole genome scan was performed to test for combined linkage and association of single markers with type 1 diabetes (19). The method used is based on a modification of Terwilliger (20) and assumes that one a priori unknown ancestral allele will be over-represented on chromosomes that carry the disease mutation. The proportion of disease chromosomes with this ancestral allele is represented by the parameter $\lambda$. The procedure was originally applied to unrelated individuals, but it can also be extended to deal with pedigree data (19). To this end, we modified the ILINK option of the LINKAGE package, version 5.04. While maximizing the log likelihood over $\lambda$, the recombination fraction was fixed at 0.01 , and the disease gene frequency was kept constant at $1 \%$, with a penetrance of $40 \%$. Markers with a $P$ value $<0.016$ were selected for further analysis.

To confirm the initial findings, the risk for type 1 diabetes was estimated for subjects carrying the ancestral allele, using the untransmitted alleles and spouses as control subjects and the type 1 diabetic patients as case subjects. We hypothesized that flanking markers of the initially significant marker should also be associated with an increased risk for diabetes. ORs are presented with $95 \%$ CIs as well as $P$ values for trend. Next, ancestral haplotype were formed, and their association with type 1 diabetes was tested.

Finally, to study a possible interaction between the newly associated markers and the high-risk HLA alleles, a stratified analysis was performed. In this analysis, the risk for type 1 diabetes was assessed in individuals with or without the HLA-DR3 or -DR4 allele.

\section{ACKNOWLEDGMENTS}

This work was supported by a grant of the Dutch Diabetes Foundation.

We would like to thank A. Jacobs and E. Wauters for their help in genotyping and P. Veraart and E. Boeren for the collection of genealogical information. For the help in collection of clinical information, we thank R.P. Rutten of Stichting Huisartsen Laboratorium Breda and the local physicians G. Dröge, Th.W.C. Snieders, P. van Wouw, M. Kraanen, W.C.J. van Broekhoven, and P. Biemond. Above all, we would like to thank the patients and relatives from the GRIP population and the municipality that made this work possible.

\section{REFERENCES}

1. Cordell HJ, Todd JA: Multifactorial inheritance in type 1 diabetes. Trends Genet 11:499-504, 1995

2. Field LL, Tobias R: Unravelling a complex trait: the genetics of insulindependent diabetes mellitus. Clin Invest Med 20:41-49, 1997

3. Buyse I, Sandkuyl LA, Zamani Ghabanbasani M, Gu XX, Bouillon R, Bex M, Dooms L, Emonds MP, Duhamel M, Marynen P, Cassiman JJ: Association of particular HLA class II alleles, haplotypes and genotypes with susceptibility to IDDM in the Belgian population. Diabetologia 37:808-817, 1994

4. Thomson G, Robinson WP, Kuhner MK, Joe S, MacDonald MJ, Gottschall JL, Barbosa J, Rich SS, Bertrams J, Baur MP, Partanen J, Tait BD, Schober
E, May WR, Ludviggson J, Lindblom B, Farid NR, Thompson C, Deschamps I: Genetic heterogeneity, modes of inheritance, and risk estimates for a joint study of Caucasians with insulin-dependent diabetes mellitus. Am J Hum Genet 43:799-816, 1988

5. Bennett ST, Todd JA: Human type 1 diabetes and the insulin gene: principles of mapping polygenes. Annu Rev Genet 30:343-370, 1996

6. Todd JA, Farrall M: Panning for gold: genome-wide scanning for linkage in type 1 diabetes. Hum Mol Genet 5:1443-1448, 1996

7. Mein CA, Esposito L, Dunn MG, Johnson GC, Timms AE, Goy JV, Smith AN, Sebag-Montefiore L, Merriman ME, Wilson AJ, Pritchard LE, Cucca F, Barnett AH, Bain SC, Todd JA: A search for type 1 diabetes susceptibility genes in families from the United Kingdom. Nat Genet 19:297-300, 1998

8. Davies JL, Kawaguchi Y, Bennett ST, Copeman JB, Cordell HJ, Pritchard LE, Reed PW, Gough SC, Jenkins SC, Palmer SM, Balfour KM, Rowe BR, Farrall M, Barnett AH, Bain SC, Todd JA: A genome-wide search for human type 1 diabetes susceptibility genes. Nature 371:130-136, 1994

9. Wright AF, Carothers AD, Pirastu M: Population choice in mapping genes for complex diseases. Nat Genet 23:397-404, 1999

10. Sheffield VC, Stone EM, Carmi R: Use of isolated inbred human populations for identification of disease genes. Trends Genet 14:391-396, 1998

11. Freimer NB, Reus VI, Escamilla MA, McInnes LA, Spesny M, Leon P, Service SK, Smith LB, Silva S, Rojas E, Gallegos A, Meza L, Fournier E, Baharloo S, Blankenship K, Tyler DJ, Batki S, Vinogradov S, Weissenbach J, Barondes SH, Sandkuijl LA: Genetic mapping using haplotype, association and linkage methods suggests a locus for severe bipolar disorder (BPI) at 18q22-q23. Nat Genet 12:436-441, 1996

12. Arnason E, Sigurgislason H, Benedikz E: Genetic homogeneity of Icelanders: fact or fiction? Nat Genet 25:373-374, 2000

13. Kuokkanen S, Gschwend M, Rioux JD, Daly MJ, Terwilliger JD, Tienari PJ, Wikstrom J, Palo J, Stein LD, Hudson TJ, Lander ES, Peltonen L: Genomewide scan of multiple sclerosis in Finnish multiplex families. Am J Hum Genet 61:1379-1387, 1997

14. Hashimoto L, Habita C, Beressi JP, Delepine M, Besse C, CambonThomsen A, Deschamps I, Rotter JI, Djoulah S, James MR, Froguel P, Weissenbach J, Lathrop GM, Julier C: Genetic mapping of a susceptibility locus for insulin-dependent diabetes mellitus on chromosome 11q. Nature 371:161-164, 1994

15. Cucca F, Esposito L, Goy JV, Merriman ME, Wilson AJ, Reed PW, Bain SC, Todd JA: Investigation of linkage of chromosome 8 to type 1 diabetes: multipoint analysis and exclusion mapping of human chromosome 8 in 593 affected sib-pair families from the U.K. and U.S. Diabetes 47:1525-1527, 1998

16. Taillon-Miller P, Bauer-Sardina I, Saccone NL, Putzel J, Laitinen T, Cao A, Kere J, Pilia G, Rice JP, Kwok PY: Juxtaposed regions of extensive and minimal linkage disequilibrium in human Xq25 and Xq28. Nat Genet $25: 324-328,2000$

17. Eaves IA, Merriman TR, Barber RA, Nutland S, Tuomilehto-Wolf E, Tuomilehto J, Cucca F, Todd JA: The genetically isolated populations of Finland and Sardinia may not be a panacea for linkage disequilibrium mapping of common disease genes. Nat Genet 25:320-323, 2000

18. Batstra MR, van Driel A, Petersen JS, van Donselaar CA, van Tol MJ, Bruining GJ, Grobbee DE, Dyrberg T, Aanstoot HJ: Glutamic acid decarboxylase antibodies in screening for autoimmune diabetes: influence of comorbidity, age, and sex on specificity and threshold values. Clin Chem 45:2269-2272, 1999

19. Escamilla MA, McInnes LA, Spesny M, Reus VI, Service SK, Shimayoshi N, Tyler DJ, Silva S, Molina J, Gallegos A, Meza L, Cruz ML, Batki S, Vinogradov S, Neylan T, Nguyen JB, Fournier E, Araya C, Barondes SH, Leon P, Sandkuijl LA, Freimer NB: Assessing the feasibility of linkage disequilibrium methods for mapping complex traits: an initial screen for bipolar disorder loci on chromosome 18. Am J Hum Genet 64:1670-1678, 1999

20. Terwilliger JD: A powerful likelihood method for the analysis of linkage disequilibrium between trait loci and one or more polymorphic marker loci. Am J Hum Genet 56:777-787, 1995 